\title{
The Teachers' Teaching Skills Affect on the Classroom Teaching Quality in the Fashion design Teaching
}

\author{
Guo Hu \\ College of Fine Arts Chongqing Normal University, Chongqing, China \\ ennhu@163.com
}

Keywords: Fashion design; Teaching skills; Teaching quality; Effect.

\begin{abstract}
The Fashion design teaching requires teachers not only to have a glib tongue,but also to do .Teachers teaching skills are important factors that affect the quality of classroom teaching. Correct understanding ofthe problems of teachers in teaching, and to take the necessary measures to make up for our own shortcomings. To fundamentally improve the effectiveness of classroom teaching quality. Before class preparation of a lesson is the key to success. Teachers should have students understandwhy to learn, what to learn, how to learn. Questions should be clear, have a stimulating and holistic .Problem chain should related as the teaching activities go on in-depth. The students think about the teacher's teaching ideas. This will not only improve the thinking ability of students but also improve teaching efficiency. The only distinctive artistic teaching skills and high-quality teachers to improve and ensure the best teaching results.

With th egreat educational reform in recent years and gradual deepening of the new curriculum reform, to create efficient classroom has become increasingly strong. But some education class reform still exists a common problem -the students do not have truly effective development of teaching efficiencies. The inefficiencies of teaching have many reasons. We need seriously study the teaching strategies, update teaching concepts, study materials, creatively use teaching materials, reform classroom teaching skills, and improve the quality of classroom teaching. How to improve the evaluation, have a good grasp of various teaching effectiveness of classroom teaching quality? In order to seek autonomy, cooperation, vibrant and efficient classroom,teaching. Combined with the experience of teaching practice and colleagues', I do some researches onthe effectiveness of survey research teaching skills.
\end{abstract}

\section{The problems in the current teaching}

The pre-class preparation inadequate, the ineffective curriculum resource Utilization. Because the quality of teachers decided to identify the scope and level of application of teaching resources. Fashion design materials are the teaching curriculum resources, and that some teachers often mistake the textbook for the only curriculum resources. Asthey do not know enough about the arts curriculum resources (teaching resources) the teaching still stucks in the "education materials. The teachers do not understand enough about the teaching plans, teaching design is not infficient.teaching objectives, focus, difficulty is not clear, teaching links repeat; not choose teaching aids, teaching media target; impervious learning situation affect the quality of classroom teaching .. On the other hand, they havethe heavy task of teachers, and do not prepare the lessons well ,etc.

Not pay enough attention to the classroom lead-in. Not innovative classroom lead-in, the lack of science, flexibility, practicality and target; The lead-in time is too long or too short, making the lead-in distracting or pale; can not quickly draws students 'attention, stimulate students' interest in learning, and the desire to learn. The purpocelesslead-in is easy to make the students feel at a loss, 
so that students do not know what to learn, why to learn and how to learn

the questions scattered, chaotic, superficial, virtual. The purpose of the questions and the idea is not clear, for questions and questions;random questions, is aimless, issue is too simple, no inspiring, can not cause students to think; important issue has not the whole idea, no the main line; lack of skills, the method is not flexible, etc. [1-2].such, Losing the integrity of the linking process of teaching.

poor control in the classroom teaching process. The ultimate purpose of the classroom teaching is through the teaching and learning activities to promote the achievement of teaching objectives. Teaching time allocation irrational, chaotic classroomdiscipline, accidental events improper handling, classroom teaching can not becarried out smoothly if the teaching target completion is not in place, it will affect the effectiveness of classroom teaching quality.

\section{Effective teaching measures in the classroom teaching}

Arts teachers often influence and determine the efficiency of the classroom. Teaching Teachers should keep practicing in the teaching process, assiduously, proficiency and flexibility in the use of a variety of teaching skills, and improve the effectiveness of classroom teaching.How do the teachers effectively solve their own problems, improve teaching efficiency?

To fully enhance the effectiveness of pre-class preparation. Before class good preparation of a lesson is the key to success. Before class do all the teaching preparatory work (to know what to teach, how to teach). The only good preparation the class will be smooth, , if not prepared or ready the lesson will be chaotic, Apparently ple-class preparation is related to the classroom teaching efficiency and quality All class preparations should focus on teaching objectives, teaching points, and the difficulty of teaching Through the teaching activities teaching focus and difficulty of teaching, will be broken through so as to promote the achievement of teaching objectives. This requires the teacher design and prepare the class well, including a careful reading and studying curriculum standards requirements and recommendations, and carefully to read and study the contents of textbooks, understand the curriculum standards in the requirements and recommendations, carefully select the teaching modes and forms teaching methods, carefully prepare teaching aids required. Note also that in the process of teaching ,the teaching content should be related to the actual life, in order to train students, ability to analyze problems and solve problems in later life.

Prior to the class, fully understand their own teaching object - their starting point. During the lesson preparation, carefully study their own students' basic knowledge and age characteristics and psychological characteristics, to consider that they have different learning requirements and learning ability, teachers can be flexible "first learn to teach academic teach and other teaching methods [2-9]. Do respect the student's personality and expertise, individualize to meet student learning needs. Allthis thefoundation to improve the effectiveness of classroom teaching quality

Classroom lead-in teaching skills. The educator Suhomlinski thinks good lead-in is the first source and spark to stimulate students' motivation to learn.Because the students are in the youth, they have a strong sense of curiosity and thirst for knowledge, so distinctive lead-in quickly to stimulate students 'interest in learning, clear about the purpose of study to attract students' attention, enter into the learning situation. as soon as possible This requires teachers to grasp the structure of the knowledge of the teaching materials; toread a broad range of fields of knowledge, cultivate rich cultural information to affect the students with scholarship charm to master the students'psychological characteristics, in order to better grasp the class lead-in skills. Situations of 
knowledge, like a soup of salt, salt dissolved in the soup can be absorbed ,knowledge into the situation, will be able to demonstrate the vitality and beautyand can be easily digested and . Situations, like an article, a story, first describe a background, and then create conflict, and raise questions Therefore, the purpose of the creation of situations, in essence, is between the known and the unknown, Through the creation of cognitive conflict propose the key issues. With the Problems we can have a funny learning activities. So good lead-in, should have a purpose, target and relevancet at the same time, interest and enlightenment. It enables the students to understand to learn, why to learn and how to learn.

Grasp the focal points and raise clever questions in teaching. In the art teaching process, to grasp the focal points and raise, clever Questions can make the teaching activition going in depth step by step.It is. beneficial to check the teaching, consolidate knowledge, promote thinking, develop students' ability to solve problems. The teachers gas a good underistanding of the texbook and the students in textbooks and students with in-depth How to improve the students' interest in learning, becomes teacher's problem .This requires the teacher to grasp the skills to ask questions in class. By asking questions the teacher can inspire the students and check his own teaching effectiveness and the curiasity about what they have learned and the innovation and the habit of guestion For example, in the form of visual representation to explain "plane constitute perceived chapters" through clever questioning to guide students to think about the problem. Enable students to produce visual illusion image "mysterious phenomenon" different form touched the potential to stimulate students motivation to learn, to mobilize the enthusiasm of student learning, Teachers can make the class smooth through "optical illusion" concept, the process and its significance and fulfil the teaching purpose to improve classroom teaching. Teacher's questions must be clear, stimulating,entirely, and the problem chains go gradually in depth through teachins activities The students can fellow the teacher's teaching ideas, so as to improve the thinking ability of the students and improve teaching efficiency.

The student is the subject of classroom teaching. Classroom control skill is a complex teaching skill. It runs through the classroom the teaching process. Teachers should continue to manage the classroom discipline, guide the students the learning, improve students' thinking, creat vivid, lively, active learning conditions for students, and make the classroom full of pleasant and harmonious learning atmosphere. Student physiological development is early and the psychological social impact is also large, They have their unique view.The teacher should create the harmonious teacher-student relationship, concern and care for students, respect the students, communicate equally ,think more about their future ,build a harmonious teaching platform, to enable students to be close to the teacher, believe the teacher. It is helpful to organize and improve the quality of classroom teaching.

\section{Conclusion}

Fashion design teachers and other subject teachers are engaged in teaching work which is related to the future of the country and the hope, the rise and fall of a nation educational success or failure depends on teachers as Maria. Torres said: " what achievements of the education of a country mainly depends on who are the country's teachers, and what they are able and willing to do. Teachers' own teaching abilities and qualities affect the quality of classroom teaching effectiveness. Therefore teachers should update their concepts, learn new curriculum ideas, have a correct understanding of the problems of teachers in teaching and have a fully preparation of lessons ,cleverly into new courses, focus on students as the main part to mobilize the enthusiasm of students learning and the entire teaching process should take positive, effective measures to 
compensate for their own inadequacies, to fundamentally improve the effectiveness of classroom teaching. The only distinctive teaching skills and high-quality teachers can improve and ensure the best teaching results

\section{References}

[1] Hau-River Fu. "New curriculum classroom teaching skills and subject teaching" [M] Beijing: World Knowledge Publishing House, 2007. P58

[2] Xingjian Liao. Efficient classroom to create sustainable development[R] .2011.12 p31

[3] Lu Zhongjie. The practice of normal school students [J]. the cause and Countermeasures of anxiety, 2011, 21 (3): 188

[4] Huang Zhong. Journal of stage fright, normal school students of Jining Teachers College in 1995 [J]., 15 (1): 28

[5] Yang Denghong [J]., existing problems and Countermeasures in teaching practice of normal school students education: Philosophy and Social Sciences Edition, 2009, 22 (6): 69-70.

[6] Zhu Xiaomin, Zhang Huling. Research on teacher education, research on [J]. effect on Gao Shisheng education development of Knowledge Science Practice Education 2010,

22 (3): 10-15.

[7] Yu Shuling, Xu CAI. American normal education practice enlightenment [J]. Journal of Daqing Polytechnic College, 1995, 25 (1): 94-96.

[8] Ji Jingwei, Hu Xiuwei. The transformation of [J]. world education information system practice teacher education in Australia, 2011 (9): 78-80.

[9] Michael Dyson. Time for Transformism in Australian Teacher Education : Evolution to A Worldview [C] .The AARE Conference, 2004. 